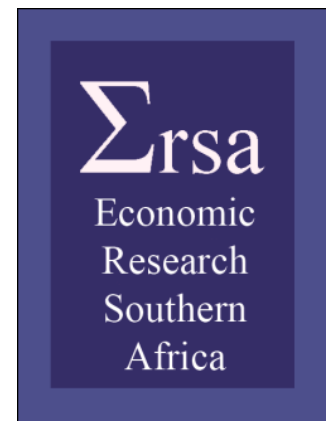

\title{
Evaluation of the effects of Reduced personal and corporate tax rates on the growth rates of the U.S. economy
}

Jacques K. Ngoie and Arnold Zellner

ERSA working paper 280

Economic Research Southern Africa (ERSA) is a research programme funded by the National Treasury of South Africa.

The views expressed are those of the author(s) and do not necessarily represent those of the funder, ERSA or the author's affiliated institution(s). ERSA shall not be liable to any person for inaccurate information or opinions contained herein. 


\title{
Evaluation of the Effects of Reduced Personal and Corporate Tax Rates on the Growth Rates of the U.S. Economy*
}

\author{
Jacques K Ngoie ${ }^{\dagger}$ and Arnold Zellner ${ }^{\ddagger}$
}

May 3, 2012

\begin{abstract}
Using several variants of a Marshallian Macroeconomic Model (MMM), see Zellner and Israilevich (2005) and Ngoie and Zellner (2012), this paper investigates how various tax rate reductions may help stimulate the U.S. economy while not adversely affecting aggregate U.S. debt. Variants of our MMM that are shown to fit past data and to perform well in forecasting experiments are employed to evaluate the effects of alternative tax policies. Using quarterly data, our one-sector MMM has been able to predict the 2008 downturn and the 2009Q3 upturn of the U.S. economy. Among other results, this study, using transfer and impulse response functions associated with our MMM, finds that permanent 5 percentage points cut in the personal income and corporate profits tax rates will cause the U.S. real GDP growth rate to rise by 3.0 percentage points with a standard error of 0.6 percentage points. Also, while this policy change leads to positive growth of the government sector, its share of total real GDP is slightly reduced. This is understandable since short run effects of tax cuts include the transfer of tax revenue from the government to the private sector. The private sector is allowed to manage a larger portion of its revenue while government is forced to cut public spending on social programs with little growth enhancing effects. This broadens private economic activities overall. Further, these tax rate policy changes stimulate the growth of the federal tax base considerably which helps to reduce annual budget deficits and the federal debt.
\end{abstract}

Keywords: Marshallian Macroeconomic Model, Disaggregation, Transfer Functions, Impulse Response Functions, U.S. Fiscal Policy Analysis.

JEL Code: E27

\footnotetext{
*This research was financed by the National Science Foundation and Economic Research Southern Africa. Opinions, conclusions or recommendations expressed in this paper are those of the authors.

${ }^{\dagger}$ University of Pretoria and University of Chicago

${ }^{\ddagger}$ University of Chicago. Arnold Zellner passed away while working on this project.
} 


\section{INTRODUCTION}

For the past three years, the United States (U.S.) has faced its most devastating economic experience since the great depression of the 1930s. Most business and consumer confidence indices have plummeted throughout this period, with a slow recovery in recent months. The strong downturn was caused by several factors including the burst of the housing bubble and the severe financial crisis. Several efforts to strengthen the U.S. economy have been undertaken including (1) the creation of $\$ 1$ trillion excess reserves by the U.S. Federal Reserve that it used for various bail-out programs and for open market operations and (2) the Federal Government's stimulus packages that totaled nearly $\$ 800$ billion. Economic experts have expressed divergent views regarding the effectiveness of these stimulus programs in promoting growth that is needed to bring about a return of the economy to full employment. Government officials have repeatedly argued that the stimulus package program was needed to rescue the U.S. economy and to prevent it from experiencing a major depression. However, the intermediate and long run growth effects of the stimulus program do not appear to have been evaluated. Also, the role of tax policy in promoting long term full employment growth has not been fully analyzed, a problem that we take up in this paper. In this connection, it is relevant to note that U.S. businesses are very highly taxed relative to businesses in many other countries; see Table 1 below. The U.S. personal income tax rates equal the OECD average which is about 42 percent (Table 1 ). Thus, it may be that cutting tax rates could be a way to stimulate the U.S. economy, a problem that we analyze below with the use of data and our Marshallian Macroeconomic Model (MMM).

As shown in Table 1, U.S. corporate income tax rates, combined income tax rates and dividend income tax rates are among the highest in the OECD group and in the world. Also, the U.S.'s personal income tax rates remain high in absolute terms although they are among the lowest in OECD countries. Thus the U.S. and some other OECD countries may be heavily taxing their populations to finance certain costly and perhaps inefficient programs. Tax cuts may help divert funds to more efficient uses, stimulate demand for output and generate growth. As regards the current state of the U.S. economy characterized with high unemployment, weak business confidence, etc., tax reforms may help (1) to reduce unemployment by creating new jobs, (2) to raise confidence in the economy, and (3) to increase consumers' and investors' expenditures.

In the current paper, we make use of several variants of our MMM to appraise the impact of personal and corporate income tax rate cuts on the growth rate of the U.S. economy. Additionally, we discuss effects of such tax rate cuts on the large budget deficit and on the size of the government sector. Our results suggest that flat rate cuts of 5 percentage points in the personal and corporate tax rates will lead to a 3.0 percentage point increase in the U.S. growth rate with a standard error of 0.6 percentage points. Assuming that both tax cuts are applied simultaneously, the annual loss in tax revenue amounts to $\$ 70$ billion while the induced GDP gain averages $\$ 377$ billion. Assuming that increased GDP leads to further increases in taxable income, the initial decline in tax 
revenue caused by the tax rate cuts will be offset by revenues from the increased taxable income that will also produce a reduction in the budget deficit.

For various reasons, there is growing pressure on world governments to reform their tax policies. It is striking to note how many firms from developed economies have relocated to low tax countries since the beginning of globalization. Many countries that have instituted tax reforms have experienced substantial growth. Below, we shall consider how changes in U.S. tax rates might affect future U.S. economic growth.

Our disaggregated model includes a government sector of which the functioning affects other sectors individually and the U.S. economy overall. Indeed, it is often very unlikely that tax cuts will have immediate short run effects for obvious reasons although they can be implemented very quickly as opposed to government spending. The question is therefore not much on the implementation but rather on the impact on targeted clusters of the economy. Fierce critics of tax cut policies have often argued that tax cuts may not necessarily lead to expected results when the targeted economic agents' reaction is contrary. For example, when agents tend to save more or pay their debts with the extra revenue obtained from personal income tax rebates. Also, firms that benefit from corporate income or profit tax or other form of tax incentives aimed at encouraging them to hire more, etc., may instead decide to use that money for salary hikes of top executives or different forms of long term investments. Among others, the Bush tax rebate of Spring 2008 aimed at stimulating the U.S. economy has averred to be a failure because it was of temporary nature. As we know, temporary tax cuts of this kind are essentially saved especially when they go to rich people who don't really need them. At the same time, people in the middle and low income group were so concerned about the future of the economy, losing their job or their house, that they could surely not use temporary tax cuts for direct spending. Instead they used it for saving or debt repayments. In our study, we propose forms of permanent tax cuts instead to avoid these detrimental effects. We conducted comparative analysis between temporary and permanent tax cuts and found the obvious: well-thought permanent tax cuts produce much better economic outcomes. Economic agents are well informed about the time nature of the tax cuts and react accordingly. When they know that the cuts will last longer and have good expectations about the recovery they will be more predisposed to spend while firms will be more inclined to hire. Otherwise, if the cuts are of temporary nature and economic agents have very little confidence in the recovery, if they are still worried about losing their jobs or not finding one, they will rather save their tax rebates for bad days to come. Firms will react in the exact same manner. Broadly speaking, most economic agents tend to restore their balance sheets before getting back to normal consumption or investment. As some have argued, we understand that the recent U.S. recession had drastic effects on the economic agents' balance sheets.

With the above discussion serving as an introduction, an overview of our paper is as follows. In the second section we provide some data relating to international personal and corporate tax rates as well as a brief discussion of a Keynesian fiscal tax rate multiplier. Then in Section 3, we explain how we shall 
use our MMM to evaluate the effects of lower tax rates on growth rates of the U.S. economy. In Section 4, we present and discuss the fitted output growth rate transfer functions of our MMM and demonstrate that they fit the actually observed growth rates and predict future growth rates rather well. Then in Section 5, we use the output growth rate transfer functions to predict the effects of tax rate cuts on the growth rate of the U.S. economy and its deficits. Finally, Section 6 provides a summary of our results and the Appendices include information about our models and techniques.

\section{BACKGROUND}

\subsection{Personal and Corporate Tax Rates}

Many countries that have instituted tax reforms have experienced substantial increases in growth. Several studies have reported that personal income tax rates have plunged over the years as more and more countries have adopted flat tax rates, e.g. Estonia and Slovakia, as a way to reduce the burden of taxation. Also, while a number of countries have reduced their corporate income tax rates, particularly in Europe, the U.S. remains among OECD countries with the highest corporate income tax rate. The idea that burdensome tax systems can curtail economic growth seems to be shared by many even though some governments continue to restrain international tax rate policy competition as carried on in the Far East. For example, Hong Kong, in strong competition with its neighbors, e.g. Singapore, after abolishing its estate tax in 2005, cut its corporate income tax rate to $16.5 \%$ from $18 \%$ in response to a tax cut by its rival Singapore (see Edwards and Mitchell, 2008) for details. As a result, this has helped Hong Kong maintain its leadership role in Asian financial markets. Other examples of tax cuts promoting growth are numerous, e.g., Malaysia, India, Australia, the Netherlands, Switzerland, etc.

Many governments of high income countries are facing growing fiscal pressures during the globalization process. They have raised expenditures to support various stimulus programs even though the cost of raising tax revenues has increased substantially. In view of the importance of these policies, attempting to cope with domestic and international problems created in part by the globalization process, for example, the mobility of tax bases helps determine a country's relative reliance on personal and corporate taxes to finance government expenses. Larger economies such as the U.S., with a less mobile tax base, as contrasted with smaller economies with mobile tax bases, tend to rely more on personal as well as corporate income taxes to finance governmental operations.

It must be recognized that many politicians have strongly opposed tax reforms that they regard as "distortions" in both the private and public sectors. However, many have also recognized that tax reforms can reduce government monopoly power and sometimes enhance governments' productive efficiency while creating opportunities for productive investments in the private 
sector. Indeed, many governments world-wide are involved in funding social programs, e.g. retirement, health, unemployment insurance, etc., and will face growing pressure to increase tax rates to finance them even though they may be very inefficient. Thus, ideally, tax reform policies should include policies to make government programs operate more efficiently.

In our current study, we consider the effects of cuts in both the personal income tax and the corporate income tax rates on the growth rate of the U.S. economy and on its deficits and debt. Our findings support the proposition that personal and corporate income tax rate cuts promote economic growth. That is, despite an initial loss in revenue, the tax cuts induce growth in the tax base and also growth in tax revenues that offset the initial losses mentioned earlier. For information on the composition of U.S. federal government receipts by tax source, see Fig.1. There it is shown that the Personal Income Tax (PIT) provides the largest source of revenue followed by Social Insurance and Retirement (SI\&R), Corporate Income Tax (CIT), Excise Taxes (ET), and other forms of taxes. Also, the gap between these different tax sources grows over time.

\subsection{Multiplier Effects in a Simple Keynesian Model}

Consider an open economy with the following product market equilibrium condition in (1) and two types of income tax rates: $t_{F}$ a flat federal income tax rate; and $t_{S}$ a flat state income tax rate. In (1), $\mathrm{Y}$ is total output, $C$ total consumption, $I$ total investment, $G$ total government expenditures, $X$ exports, and $Z$ imports:

$$
Y=C+I+G+X-Z
$$

Then on introducing a consumption function shown in (2) with $\bar{C}$ the autonomous consumption and $c$ the marginal propensity to consume. Also, assuming I, G and NX = X - Z exogenous, we have:

$$
C=\bar{C}+c\left(1-t_{F}-t_{S}\right) Y
$$

and with $I=\bar{I}, G=\bar{G}, N X=\bar{N} \bar{X},(1)$ can be written as follows:

$$
Y=\bar{C}+c\left(1-t_{F}-t_{S}\right) Y+\bar{I}+\bar{G}+\bar{N} \bar{X}
$$

Then, the reduced form, multiplier equation for $Y$ is:

$$
Y=\frac{\bar{C}+\bar{I}+\bar{G}+\bar{N} \bar{X}}{1-c\left(1-t_{F}-t_{S}\right)}
$$

and the Keynesian multiplier $=\frac{1}{1-c\left(1-t_{F}-t_{S}\right)}$.

From this simple multiplier, any federal or state income tax cut that is not offset generates an increase in Y. The literature on fiscal multipliers contains multipliers that are much more complex and more comprehensive although the rationale remains the same: tax cuts induce growth in Y, ceteris paribus. Also, since tax rate cuts increase the value of the Keynesian multiplier, the effects of 
government stimulus packages will be enhanced under the assumption that the Keynesian multiplier equation is dependable in predicting outcomes.

Tax cut helps transfe rmoney from the government to the private. The use of such surplus money is determined by private economic agents' expectations of the future of the economy and the nature of the tax cut. If they perceive it as permanent in nature within an economy with growing confidence when it comes to job creation, business investments, etc., economic agents will spend that money. This will result in increased economic activities and help recover in tax revenue.

\section{MODEL SPECIFICATION}

Our modeling work involves use of aggregate and disaggregate variants of our MMM of the U.S. economy. The aggregate variant of our MMM considers the U.S. economy as a whole - a one-sector economy - while the disaggregated variants represent the U.S. economy as divided into 16 interdependent industrial sectors, the 16-sector MMM. The one-sector and the 16-sector variants of our MMM include two types of markets, namely, (1) product markets and (2) factor markets. The product markets are modeled to include usual demand and supply functions. Also, on aggregating over firms, the industry supply function depends on the number of firms in operation. The number of firms in operation variable is modeled by use of a Marshallian entry-exit equation in which firms' profits is a key variable. Additionally, Marshallian modeling includes traditional factor markets for labor, capital and money. Firms in operation as well as government productive units demand labor, capital and money services in the factor markets. Also, consumers demand money services in the money market and the government supplies money to it. Consumer units supply labor and savings to the factor markets and the government supplies money to the money market (see, e.g., Zellner and Israilevich (2005), Ngoie and Zellner (2012) and below for details.) In addition, the government implements various tax rates, monetary and expenditure policies.

Thus our MMM includes (1) sector supply equations derived by aggregating individual firms' supply functions, (2) sector product demand equations derived by aggregating individual consumers' demand functions with inclusion of demand shifters, (3) sector firm entry-exit equations, and (4) factor demand and supply functions. Firms are assumed to be profit- maximizers using CobbDouglas production functions. In addition, as mentioned above, the model has a government sector that produces output, demands inputs, supplies money, taxes and implements various fiscal and monetary policies.

In what follows, we describe the development of a one-sector MMM with reduced form and transfer function equations and then go on to describe our 16-sector MMM of the U.S. economy and its properties. 


\subsection{Variant I: A One-Sector MMM}

\subsubsection{Production function}

Assume that the $i^{\text {th }}$ firm operates with a Cobb-Douglas production function,

$$
Q_{i t}=A_{i t}^{*} L_{i t}^{\alpha} K_{i t}^{\beta}
$$

where $A_{i t}^{*}=A_{N i t} \cdot A_{L i t} \cdot A_{K i t}$, the product of neutral, labor enhancing and capital enhancing technological change factors; see Zellner and Israilevich (2005).

Given the price of output and the prices of inputs and profit maximization under competitive conditions, we derive the $i^{\text {th }}$ firm's output supply function that we multiply by current price to obtain the firm's "sales supply" function that we aggregate over firms in operation in the sector to yield the "sector sales supply" function given in (6).

$$
S_{S t}=N_{t}\left(A_{t} P_{t}\right)^{\frac{1}{\delta}} W_{t}^{\frac{-\alpha}{\delta}} R_{t}^{\frac{-\beta}{\delta}}
$$

with $\delta=1-\alpha-\beta-\varphi, 0<\delta<1$

where $N$ is the number of firms, $A$, the technological factor productivity, $P$, the output price, $W$, the wage rate, and $R$, the interest rate. Logging both sides of (6) and differentiating with respect to $t$, we obtain the following sales equation expressed in growth rate terms.

$$
\frac{\dot{S}_{S t}}{S_{S t}}=\frac{\dot{N}_{t}}{N_{t}}+\frac{1}{\delta}\left(\frac{\dot{A}_{t}}{A_{t}}+\frac{\dot{P}_{t}}{P_{t}}\right)-\frac{\alpha}{\delta} \cdot \frac{\dot{W}_{t}}{W_{t}}-\frac{\beta}{\delta} \cdot \frac{\dot{R}_{t}}{R_{t}}
$$

Similarly, on multiplying both sides of the consumers' demand function for output price, we have the following "product sales demand function":

$$
S_{D t}=P_{t} Q_{t}=D P_{t}^{1-\theta} Y_{t}^{\theta_{s}} H_{t}^{\theta_{H}} \prod_{j=1}^{n} X_{j t}^{\theta_{j}}
$$

Logging both sides and differentiating with respect to time we obtain the sales demand equation expressed in growth rate terms.

$$
\frac{\dot{S}_{D t}}{S_{D t}}=(1-\theta) \frac{\dot{P}_{t}}{P_{t}}+\theta_{S} \frac{\dot{Y}_{t}}{Y_{t}}+\theta_{H} \frac{\dot{H}_{t}}{H_{t}}+\sum_{j=1}^{n} \theta_{j} \frac{\dot{X}_{j t}}{X_{j t}}
$$

In (8) and (9), $Y$ is personal disposable income, $H$, the number of households, $X$, the demand shifters (with $\mathrm{n}$, the number of demand shifters), and $D$, a constant. In a one sector economy with taxes, if $\theta=\theta_{S}$ there is no money illusion. We refer to money illusion as the general leaning of economic agents to consider currency in nominal rather than real terms. This entails a blatant confusion between face value of money and its purchasing power. 


\subsubsection{Entry-Exit Equation}

As mentioned earlier, the firm entry-exit equation, which is the third equation in our product market model, represents a dynamic process that can produce long run equilibrium for the product market, as is well known and explained in price theory texts. That is firms enter the industry when economic profits are positive and leave the industry when economic profits are negative and give rise to associated shifts in the industry supply function that we represent in the following equation:

$$
\frac{\dot{N}_{t}}{N_{t}}=C_{E} \pi_{t}
$$

In (10), the market profit within a given sector at time $t$ is equal to $\pi_{t}$. Given profit maximization and the Cobb-Douglas specification, a firm's profit $\pi$ is equal to a proportion $\eta$ of its sales $S_{S}$, that is $\pi_{t}=\eta S_{S t}$; we can transform (10) as follows

$$
\frac{\dot{N}_{t}}{N_{t}}=C_{E} \eta S_{S t}
$$

with $C_{E}$ being a constant term that includes other determinants.

\subsection{Factor markets}

\subsubsection{Labor}

\section{Labor Supply Equation}

$$
L_{t}=D_{L t}\left(\frac{W_{t}}{P_{t}}\right)^{\gamma}\left(\frac{Y_{t}}{P_{t}}\right)^{\gamma s} H_{t}^{\gamma_{H}} \sum_{j=1}^{d} \gamma_{j} z_{j t}
$$

where $D_{L}$ is the total number of labor providers (mainly households) within the sector while $z$ represent the labor supply shifters. Then logging (12) and differentiating with respect to time, we have

$$
\frac{\dot{L}_{t}}{L_{t}}=\frac{\dot{D}_{L t}}{D_{L t}}+\gamma\left(\frac{\dot{W}_{t}}{W_{t}}-\frac{\dot{P}_{t}}{P_{t}}\right)+\gamma_{s}\left(\frac{\dot{Y}_{t}}{Y_{t}}-\frac{\dot{P}_{t}}{P_{t}}\right)+\gamma_{H} \frac{\dot{H}_{t}}{H_{t}}+\sum_{j=1}^{d} \gamma_{j} z_{j t}
$$

Labor Demand Equation The demand for labor, derived from profit maximization on the part of firms is given by

$$
\begin{gathered}
L_{t}=\frac{\alpha N_{t} P_{t} Q_{t}}{W_{t}} \\
L_{t}=\alpha \frac{S_{t}}{W_{t}}
\end{gathered}
$$

Assuming fixed parameters and logging both sides of (14) and differentiating with respect to time we obtain the following

$$
\frac{\dot{L}_{t}}{L_{t}}=\frac{\dot{S}_{t}}{S_{t}}-\frac{\dot{W}_{t}}{W_{t}}
$$




\subsubsection{Capital}

As with labor, capital equations are obtained from firms' profit maximization conditions.

\section{Capital Supply Equation}

$$
\begin{gathered}
K_{t}=E_{t}\left(\frac{R_{t}}{P_{t}}\right)^{\phi}\left(\frac{Y_{t}}{Y_{t}}\right)^{\phi_{s}} H_{t}^{\phi_{H}} \sum_{j=1}^{n} v_{j t}^{\phi_{j}} \\
\frac{\dot{K}_{t}}{K_{t}}=\frac{\dot{E}_{t}}{E_{t}}+\phi\left(\frac{\dot{R}_{t}}{R_{t}}-\frac{\dot{P}_{t}}{P_{t}}\right)+\phi_{s}\left(\frac{\dot{Y}_{t}}{Y_{t}}-\frac{\dot{P}_{t}}{P_{t}}\right)+\phi_{H} \frac{H_{t}}{H}+\sum_{j=1}^{n} \phi_{j} v_{j t}
\end{gathered}
$$

where $E$ represents the total number of capital providers that includes (1) Government, (2) Domestic providers, and (3) Foreign providers, $v$ represents the capital supply shifters, and $R$ the real interest rate.

\section{Capital Demand Equation}

$$
\begin{aligned}
K_{t} & =\frac{\beta N_{t} P_{t} Q_{t}}{R_{t}} \\
K & =\beta \frac{S_{t}}{R_{t}}
\end{aligned}
$$

(18) can be transformed as follows:

$$
\frac{\dot{K}_{t}}{K_{t}}=\frac{\dot{S}_{t}}{S_{t}}-\frac{\dot{R}_{t}}{R_{t}}
$$

Solving analytically for the reduced form equations in the factor markets we obtain the following.

For labor,

$$
\begin{gathered}
\frac{\dot{S}_{t}}{S_{t}}-\frac{\dot{W}_{t}}{W_{t}}=\frac{\dot{D}_{L t}}{D_{L t}}+\gamma \frac{\dot{W}_{t}}{W_{t}}-\gamma \frac{\dot{P}_{t}}{P_{t}}+\gamma_{s} \frac{\dot{Y}_{t}}{Y_{t}}-\gamma_{s} \frac{\dot{P}_{t}}{P_{t}}+\gamma_{H} \frac{\dot{H}_{t}}{H_{t}}+\sum_{j=1}^{d} \gamma_{j} z_{j t} \\
(1+\gamma) \frac{\dot{W}_{t}}{W_{t}}=\frac{\dot{S}_{t}}{S_{t}}-\frac{\dot{D}_{L t}}{D_{L t}}+\gamma \frac{\dot{P}_{t}}{P_{t}}-\gamma_{s} \frac{\dot{Y}_{t}}{Y_{t}}+\gamma_{s} \frac{\dot{P}_{t}}{P_{t}}-\gamma_{H} \frac{\dot{H}_{t}}{H_{t}}-\sum_{j=1}^{d} \gamma_{j} z_{j t} \\
\frac{\dot{W}_{t}}{W_{t}}=\left(\frac{1}{1+\gamma}\right) \frac{\dot{S}_{t}}{S_{t}}+\left(\frac{\gamma+\gamma}{1+\gamma}\right) \frac{\dot{P}_{t}}{P_{t}}-\left(\frac{\gamma_{s}}{1+\gamma}\right) \frac{\dot{Y}_{t}}{Y_{t}}-\left(\frac{\gamma_{H}}{1+\gamma}\right) \frac{\dot{H}_{t}}{H_{t}}-\sum_{j=1}^{d}\left(\frac{\gamma_{j}}{1+\gamma}\right) z_{j t}
\end{gathered}
$$

And for capital:

$$
\frac{\dot{S}_{t}}{S_{t}}-\frac{\dot{R}_{t}}{R_{t}}=\frac{\dot{E}_{t}}{E_{t}}+\phi \frac{\dot{R}_{t}}{R_{t}}-\phi \frac{\dot{P}_{t}}{P_{t}}+\phi_{s} \frac{\dot{Y}_{t}}{Y_{t}}-\phi_{s} \frac{\dot{P}_{t}}{P_{t}}+\phi_{H} \frac{\dot{H}_{t}}{H}+\sum_{j=1}^{n} \phi_{j} v_{j t}
$$




$$
\begin{gathered}
(1+\phi) \frac{\dot{R}_{t}}{R_{t}}=\frac{\dot{S}_{t}}{S_{t}}-\frac{\dot{E}_{t}}{E_{t}}+\left(\phi+\phi_{s}\right) \frac{\dot{P}_{t}}{P_{t}}-\phi_{s} \frac{\dot{Y}_{t}}{Y_{t}}-\phi_{H} \frac{\dot{H}_{t}}{H_{t}}-\sum_{j=1}^{n} \phi_{j} v_{j t} \\
\frac{\dot{R}_{t}}{R_{t}}=\left(\frac{1}{1+\phi}\right)\left[\frac{\dot{S}_{t}}{S_{t}}-\frac{\dot{E}_{t}}{E_{t}}+\left(\phi+\phi_{s}\right) \frac{\dot{P}_{t}}{P_{t}}-\phi_{s} \frac{\dot{Y}_{t}}{Y_{t}}-\phi_{H} \frac{\dot{H}_{t}}{H_{t}}-\sum_{j=1}^{n} \phi_{j} v_{j t}\right]
\end{gathered}
$$

Using the current-looking Taylor rule (Barnett, 2008), the interest rate function can be formulated as follows:

$$
R_{t}=c_{1} \pi_{t}+c_{2} x_{t}
$$

where $c_{1}$ is the coefficient of the central bank's reaction to inflation, $\pi_{t}$ is the inflation rate, $c_{2}$ is the coefficient of the central bank's reaction to output and $x_{t}$ is the output gap.

Solving analytically for the system of equations relating to the product market, we have:

$$
\begin{gathered}
(1-\theta) \frac{\dot{P}_{t}}{P_{t}}=\left(1-\theta_{s}\right) \frac{\dot{S}_{t}}{S_{t}}-\theta_{H} \frac{\dot{H}_{t}}{H_{t}}-\sum_{j=1}^{n} \theta_{j} \frac{\dot{X}_{j t}}{X_{j t}} \\
\frac{\dot{P}_{t}}{P_{t}}=\frac{1}{(1-\theta)}\left[\left(1-\theta_{s}\right) \frac{\dot{S}_{t}}{S_{t}}-\theta_{H} \frac{\dot{H}_{t}}{H_{t}}-\sum_{j=1}^{n} \theta_{j} \frac{\dot{X}_{j t}}{X_{j t}}\right]
\end{gathered}
$$

\subsubsection{Transfer functions}

There is a large literature on alternative algebraic forms of dynamic simultaneous equations models. For example, our MMM has several algebraic well known representations such as restricted or unrestricted reduced form equations, final equations, transfer function equations, etc. (see, e.g. Zellner and Palm (2004), Ngoie and Zellner (2010)). In this paper, we find that the transfer functions are much more useful than other representations, especially since we do not have data on all the endogenous variables in the model.

Transfer functions relate current values of each endogenous variable to its own lagged values and to current and lagged values of the exogenous variables; see Quenouille (1957). Thus we can fit the transfer functions for a subset of endogenous variables for which we have data and use them to predict their future values. Details about the derivation of transfer functions from linear multiple time series processes as used in this study have been provided in a previous study; see Ngoie and Zellner (2012). The transfer functions for our one-sector MMM product markets with $H_{11}, H_{12}$ and $F_{12}$ representing matrices of lag operators are given by:

$$
\left|H_{11}\right| x_{1 t}=-H_{11}^{a d j} H_{12}(L) x_{2 t}+H_{11}^{a d j} F_{11}(L) \varepsilon_{1 t}
$$

where $x_{1 t}=\left(s_{t}, p_{t}, n_{t}\right)^{\prime}$ is the vector of endogenous variables, $x_{2 t}=\left(w_{t}, r_{t}, m 2_{t}\right.$, $\left.s p_{t}, c t a x_{t}, y_{t}, i z_{t}, h_{t}\right)^{\prime}$ is the vector of exogenous variables, and $\varepsilon_{1 t}=\left(\mu_{1 t}, \mu_{2 t}, \mu_{3 t}\right)^{\prime}$ 
is the vector of error terms. Also, $x_{1 t}$ is exogenous in the product market. The transfer functions for a one-sector MMM that includes factor markets and the government sector can also be specified using (28). We make use of small letters to represent the growth rates of the variables and the corresponding capital letters for level variables, e.g., $\ln \left(\frac{S_{t}}{S_{t-1}}\right)=s_{t}$. Thus, in vector $x_{2 t}, w$ is used for the rate of growth of the real wage, $r$ the interest rate, $s p$ the stock price, $m 2$ the money supply, ctax the corporate tax, $y$ real disposable income, $h$ the number of households, and $i z$ total world imports. In the vector of endogenous variables $x_{1 t}, s$ represents the rate of growth of real sales, $p$ represents the inflation rate and $n$ the rate of growth of number of operating firms.

We made use of well-known Box Jenkins transfer functions identification techniques (see Box and Jenkins, 1976) and our estimated autocorrelation and partial autocorrelation functions are presented in Table A1. In future work, we plan to draw on alternative model identification techniques.

In Table A1, we report estimation results of our autocorrelation and partial autocorrelation functions together with the Q-statistic. These results have been obtained from autocorrelation and partial autocorrelation functions to portray pattern of temporal dependence in the residuals. Should the correlation coefficients of the series die off geometrically while lags increase, the series is said to obey an autoregressive process of low order. The faster the correlation coefficient drops to zero after few lags the lower is the order of the moving average process. In Table A1 the autocorrelation is within the approximate two standard error bounds. Therefore, it is not significantly different from zero at 5 percent level of significance. Also, this table includes results for partial autocorrelation coefficients. They measure the correlation of the residual values that are $n$ periods apart after the correlation has been removed from the interesting lags. These coefficients are estimated recursively using the Box-Jenkins algorithm; see Box and Jenkins 1976. The last column of Table A1 reports the Ljung-Box Q-statistic (Ljung and Box, 1978). This test is used to determine whether the series is white noise or not. Our MMM-DA does not present autocorrelation or partial autocorrelation problems as one could suspect for transfer functions systems derived from multiple structural equations. As shown in Ngoie and Zellner (2012), the MMM-DA includes functions from the structural equations system which comprises product market equations, factors markets equations and firms' entry and exit equations at sectoral level. Should there be any white noise error terms introduced in these equations, error terms in the transfer functions will be autocorrelated. Subsequently, should error terms in the structural equations be autocorrelated, then error terms in the transfer equations system might present different properties such as moving average or white noise to some instance. Therefore, it was decisive to perform related testing on error terms of our transfer functions system. So far, the tests performed using Generalized Least Square (GLS) criterion have revealed no autocorrelation. In Fig A1, we present plots of error terms of our estimated transfer functions for each sector of the U.S. economy. 


\subsection{Variant II: 16 -sector MMM}

Considering the advantages of disaggregation discussed and demonstrated in the literature, we decided to disaggregate our one sector MMM into a 16 sector MMM of the US economy. The formulation of the transfer function system remains the same as for individual sectors with an additional subscript describing the appropriate sector and estimation is performed using iterative seemingly unrelated regression (ISUR) techniques with estimation results justified in both sampling theory and Bayesian terms. That is, it is well known that the ISUR technique produces estimates that are consistent and asymptotically efficient and equivalent to maximum likelihood estimates and Bayesian estimates in large samples. Further, with a diffuse prior and a normal likelihood function, the ISUR estimate is the modal value of the posterior density that is an optimal point estimate vis-á-vis a zero-one loss function. Moreover, for the implementation of our ISUR, the assumed covariance matrix allows contemporaneous correlation within and across industries. With this said about theoretical properties of our estimation technique, we now turn to a presentation and discussion of our empirical results.

\section{RESULTS: MODEL FIT AND PREDICTIVE PERFORMANCE}

\subsection{One-sector MMM}

\subsubsection{Annual data}

Using annual data for the U.S. economy from 1987 to 2008, we have (1) estimated our transfer function for $s_{i t}$, the rate of growth of real sales of sector $i$ in period $t,(2)$ checked its fit to the data, (3) assessed its predictive ability using two criteria (MAE and RMSE), and (4) subjected the model to a set of tax cuts that are discussed in Section V. As shown in Fig. 2 below, the model fits the data reasonably well.

Considering the above MAE and RMSE of forecasts in Table 2, our model estimated using annual data yielded rather good predictions for the U.S. economy's growth rates. The MAE and RMSE of one year-ahead forecast are below average figures discussed in the literature. Usually MAE and RMSE values of good forecasts for the U.S. GDP or GNP range between 0.8 and 1.5 percentage points (Zarnowitz, 1992).

\subsubsection{Quarterly data}

The one sector MMM has been used to forecast quarterly data for the U.S. economy from 2000Q1 to 2009Q3 updating the estimates quarter by quarter. The model fits well (see Fig.3a and 3b) and it has been able to predict reasonably well the 2008 downturn of the U.S. economy; see results in Fig. 3b. Note that at 
present, few macroeconomic models have been able to predict cyclical downturns and upturns very well.

At this stage, our one quarter-ahead forecast results include forecasts with known values of the exogenous variables (Fig. 3a) and forecasts with unknown values of the exogenous variables (Fig. 3b). In both cases our model forecasts are reasonably accurate and the downturn of 2008 and the 2009Q3 upturn are accurately forecasted. As expected, forecasting with forecasted exogenous variables results in slightly higher errors (see Table 3).

\subsection{6-sector MMM}

Since, as many have pointed out, thoughtful disaggregation may produce improved estimation as well as forecasting results and better policy evaluations, we have estimated transfer functions for the quarterly rates of growth of real sector sales for each of 16 sectors of the U.S. economy. The estimation results have been obtained by estimating the 16 sector transfer functions jointly using iterative seemingly unrelated regression techniques. The sample size used for the 16-sector MMM is smaller than that used in our calculations with the one sector MMM because of major modifications that occurred in the U.S. industry classification ${ }^{1}$. Due to these modifications, longer series for sectors such as 'Utilities' could simply not be obtained or they would have involved further and complicated data manipulations.

As for the predictive performance of the 16-sector MMM using annual data, the small sample size (only 20 observations) coupled with the use of lagged series which reduces even more the sample size make it difficult to compare the forecasting ability of this variant of the model with that of a one-sector MMM. However, for the few point forecasts obtained, the MAFEs and RMSFEs are lower than for those of the one-sector MMM in forecasting aggregate real GDP growth rates, in line with certain theoretical results in the literature; see, e.g. de Alba and Zellner (1991). They show that in terms of aggregating standard multiple regression models with a common regression coefficient vector there is a loss of precision of estimation and prediction in using the aggregate relation rather than the disaggregated relations even though there is no aggregation bias associated with the use of their particular model.

\footnotetext{
${ }^{1}$ The U.S. SIC (Standard Industrial Classification) divisions, originally created in the early 1930 s to provide classification of establishments by type of activity, came under severe scrutiny due to major changes in the U.S. as well as the world economies. The last update of SIC data occurred in 1987 raising the need for us to make use of NAICS data for the period post 1987. Also there are fundamental differences between SIC data and NAICS data when it comes to industry classification. NAICS series are more disaggregated and industries' grouping is substantially different between the types of classification. For example, 'utilities' is a separate sector in NAICS data while 'utilities' are associated with 'Transportation and Communications' in SIC divisions. The same applies to (1) Retail Trade, (2) Finance, (3) other services, etc.
} 


\subsubsection{MMM versus other Macroeconomic Models}

In addition, to illustrate further the quality of the MMM's relative forecasting performance, we have in Table 4 compared its mean squared forecast errors (MSFEs) and root mean squared forecast errors (RMSFEs) to those of three currently popular macroeconomic models, a Global VAR (Vector Autoregressive), a Bayesian VAR and a DSGE (Dynamic Stochastic General Equilibrium). In previous studies (Ngoie and Zellner, 2010), relative forecasting performance of our MMM and MMM-DA have been established while comparing its RMSFEs and MSFEs to those of an ARLI-3 (Autoregressive Leading Indicator of order 3 ).

It is important to emphasize here that MSFEs and RMSFEs of other models reported in Table 4 have not been computed in our study. As indicated in the footnote of Table 4, these results have been obtained from the literature; see Giannone and Reichlin (2009) for the GVAR and BVAR, and Smets and Wouters (2007) for the DSGE. Indeed, fitting and forecasting using a DSGE model is a non-trivial exercise with results highly contingent on the priors. We therefore insist that results of this relative comparison might be affected by modeling assumptions. The stated aims of our study remain the fit, predictive performance and policy guidance ability of our MMM-DA and its different variants. Needless to say it will be a very insightful exercise to conduct by ourselves fit and forecasts using other models cited in Table 4 and have more precise grounds of comparison. But that is considered for further work.

At this stage, what we believe is the key driver of the relative predictive performance of our MMM as opposed to these other models include the use of firms' entry/exit functions as a way to move across different equilibrium positions. While using our MMM-DA, disaggregation is an additional booster of our model's forecasting performance.

As clearly shown in Table 4, the MMM forecasts have lower RMSFEs and MSFEs than those for the GVAR, the BVAR and the DSGE models. However, this observation needs to be taken with caution since the compared forecasts were evaluated over different sample periods. This raises the possibility of aggregation biases resulting, among others, from the neglect of distributional aspects of the data. But it is important to note that the sample period covered by our MMM includes the 2008 recession with the collapse of financial institutions and the 2009 Q3 recovery.

\section{POLICY EVALUATIONS}

\subsection{The One-Sector MMM using Annual Data}

As described in our introduction, the main focus of our policy study is to determine how the U.S. GDP growth rate is affected by changes in the personal income tax rate and the corporate income tax rate.

As largely agreed upon in the literature, permanent tax rate cuts produce larger growth effects than those associated with temporary cuts. The underlying 
assumption being that temporary cuts keep consumers cautious and lead them to save more instead of raising consumption. However, permanent cuts affecting the permanent component of income generate larger growth in spending in accord with some well-known theories of consumer behavior. In this study, the difference between permanent and temporary is established based on the length of shocks to tax variables.

\subsection{The 16-sector MMM}

In this section, we report the results of applying our suggested policy changes to the 16-sector MMM of the U.S. economy.

As discussed in Ngoie and Zellner (2012), disaggregation has several desirable qualities that include the ability to describe how policy shocks affect individual sectors of an economy. Previous studies have established that disaggregated models are far more appropriate in explaining and predicting sectors' disparate behavior and that use of them leads to more accurate precise predictions and possibly to improved policy recommendations. Additionally, the use of aggregate models leads to loss of prediction accuracy as shown in de Alba and Zellner (1991), Zellner and Tobias (2000), and Zellner and Israilevich (2005). As shown in Table 6, sectors of the U.S. economy portray different output growth increases. It is obviously not surprising that flat income and corporate tax cuts do not affect sectors in the same manner. Some sectors tend to be more sensitive to such shocks than others. For example, Information portrays one of the highest tax cuts effect on the sector's growth. Along the line, Wholesale, Retail Trade, Professional and Business Services, and Manufacturing depict substantial effects of tax cuts on economic growth. Further investigation might be required to extract a complete explanation of such disparity in tax cuts effects but what we have in Table 6 is plausible. These are sectors that are very sensitive to business cycle fluctuations and therefore depict procyclical patterns. Policies that are meant to boost economic growth will most likely affect them to a greater extend. However, the magnitude of tax cuts effects on the growth of the agriculture sector seems unusually high. Also, in Table 6 , it is noticeable that the standard errors of forecast obtained from the 16-sector MMM are substantially smaller than those of the one-sector MMM.

\subsection{Impact of suggested tax cuts on the size of the US Government sector}

It is seen from Table 6 that all the sectors, including government, exhibit positive economic growth. However, as the growth of the government sector appears to be smaller than the growth of other sectors, the size of the government sector as a share of total GDP is somewhat reduced. Although a large fraction of government activities is financed through tax revenue, the government sector also produces goods and services that are sold to businesses and private consumers. Therefore, increased disposable income coupled with increased corporate income lead to higher demand for government products. Additionally, as we mentioned 
earlier, the suggested tax cuts lead to an increase in the country's GDP and higher tax revenues.

There is a large literature on the growth-maximizing level of government size; see Barro 1990, Rahn et al 1996, Scully 1998 and 2003. These authors argue that when the government sector is too large it generates several externalities and distortions in the economy. The present study does not provide enough empirical evidence to support nor refute such statement. However, the literature cited includes findings that present compelling evidence that overly large government sector tends to reduce economic growth. The government will be inclined to spend more on pompous social programs that have little direct and sustainable effects on economic growth. Yet we perfectly understand and acknowledge that economic development is contingent to a secured and sustainable environment. And the government plays a leading role in making provision for such an environment that foster operation of a market economy. Notwithstanding, the government provides public goods conducive to economic growth.

\subsection{Impact of suggested policies on budget deficit}

While suggesting tax cuts as a path for stimulating the U.S. economy, it is important to address the issue of budget deficit as of first order effect. The U.S. budget deficit is large and is expected to get even larger (see Figs. 4, 5 and 6). Although the U.S. government has undertaken a series of public spending freeze for the coming years, the concern remains. Therefore, the reforms proposed in this study are also meant to address somehow this issue.

From Fig. 5, it is observable that the cyclical component of the U.S. budget deficit is significant. Therefore, the role of automatic stabilizers, fiscal or nonfiscal, such as tax revenue should be well emphasized. Tax revenue rises during economic upturns and decline during downturns. However, tax cuts imposed during economic dips that lead to higher economic activities have countercyclical effects and therefore help with the economic recovery.

Supply-side economists have provided several arguments in support of tax cuts as engine of growth. Any tax cut leads to a decline in tax revenue. Obviously, less government revenue hinders the country's growth only if government has an optimal spending framework. However, there is evidence that government does not spend optimally. Therefore, instead of having the government spending tax revenue, tax cuts allow private initiatives which in most cases are more productive. Some clearly indicate that a large federal budget most likely results in slower growth especially when most of the government spending targets social programs. In case of the United States, a substantial portion (nearly half) of the federal budget is used for transfers, e.g. Social Security. It is therefore important to understand that tax cuts, when carefully implemented, can reduce or avoid distortions created by direct government spending.

In this study, we do not use our MMM-DA to forecast government spending as this might require more features to our model. Instead, we simply make use of BEA forecasts to this regard and these forecasts suggest a substantial decline in government spending (see Fig. 4) in the after-stimulus years. Our 
results on the impact of permanent tax cuts on budget deficit are therefore highly sensitive to BEA forecasts. With the use of our MMM-DA, we simulate an increase of 3 percentage points of taxable income as a result of real GDP growth (see Fig.6) while expenditures are obtained from BEA forecasts. The results we present in Fig. 6 are therefore liable to our different priors. Although different prior information may lead to different results, the general conclusion to be drawn remains the same: well-targeted and well-implemented tax cuts help raise taxable income and produce reduced budget deficits when government spending is decreased.

With respect to Fig. 6, we see that long term U.S. budget deficit will be substantially reduced over time as a result of our suggested reforms. The underlying reason is that in the long run tax cuts stimulate a boost in the GDP growth rate, which in turn induces a substantial increase in government revenues to such an extent that the increase offsets the loss incurred by the tax cut. However, such a finding is conditioned by tax cuts being supported by other fiscal and non-fiscal actions. For example, a federal tax rate cut that is offset by a hike in state tax rates will obviously not produce the same results as reported above.

As there is no such a thing as free lunch, despite supportive points discussed at length in this study, permanent tax cuts cost a lot of money to the government and harshly affect public spending. For this reason, some pundits and researchers have raised major concerns about how such tax cuts could affect the budget deficit which is already in tatter. The best way to keep track of the budget deficit on the very short run is to substantially decrease government spending along with the proposed tax cuts. Permanent tax cuts will not help reduce the budget deficits without a sharp decline in public spending.

\section{CONCLUSION}

In the present research, we have considered the economic growth impact of tax rate cuts on the U.S. economy using variants of our Marshallian macroeconomic model. Before analyzing the effects of alternative policies, we provided evidence that our MMM-DA fits the data and predicts well. Two variants of our MMMDA model using annual and quarterly data were employed to evaluate the effects of tax cut policies. We have simulated a set of permanent and temporary flat tax cuts on personal income and corporate income using U.S. data. The results in this paper indicate that permanent as opposed to temporary cuts induce larger growth effects and that personal income tax rate cuts produce larger growth effects as compared to those associated with corporate income tax cuts. If carefully implemented, our Marsahallian model predicts that permanent cuts of 5 percentage points in the personal and corporate income tax rates will induce an increase of 3 percentage points in the annual U.S. GDP growth rate. Additionally, our findings suggest that the government sector, like other sectors, will grow in absolute size but decrease in relative size as a result of the proposed tax reforms. 
Concerning tax cuts' implications for the budget deficit, this paper provides a forecast of the U.S. deficit until 2015 using our MMM-DA. We then compared the U.S. BEA forecast of the budget deficit to our forecast with the suggested tax cuts. The findings clearly establish the effectiveness of our suggested reforms in helping reduce the U.S. budget deficit over time.

In future work, we intend to improve our MMM-DA that will help address as yet untreated issues such as (1) the shadow or underground economy, (2) inventory investment, (3) imperfect competition in some sectors, (4) imports and exports by industrial sector, etc. While much remains to be done, we do find our current MMM-DA to be a useful tool for analysis, prediction and policy guidance.

\section{References}

[1] Barnett, W.A. and Duzhak, E.A. (2008) Empirical Assessment of Bifurcation Regions within New Keynesian Models. MPRA, Working Paper no. 11249 .

[2] Barro, R. (1990) Government Spending in a Simple Model of Endogenous Growth. Journal of Political Economy. Vol. 98, no. S5.

[3] Baxter, M. and King, R.G. (1999) Measuring Business Cycles: Approximate Band-Pass Filters For Economic Time Series. The Review of Economic and Statistics. Vol. 81 (4), 575 - 593.

[4] Box, G.E.P. and Jenkins, G.M. (1976) Time Series Analysis: Forecasting and Control. Holden-Day.

[5] de Alba, E. and Zellner, A. (1991) Aggregation, Disaggregation, Predictive Precision and Modeling. HGB Working Paper Series.

[6] Edwards, C. and Mitchell, D. (2008) Global Tax Revolution. Cato Institute.

[7] Giannone, D. and Reichlin, L. (2009) Comments on Forecasting Economic and Financial Variables with Global VARs. International Journal of Forecasting. Vol. 25, 684-686.

[8] Ljung-Box, G.M. and Box, G.E.P. (1978) On a Measure of a Lack of Fit in Time Series Models. Biometrika. Vol. 65, 297-303.

[9] Ngoie, K.J. and Zellner, A. (2012) The Use of a Marshallian Macroeconomic Model for Policy Evaluation: Case of South Africa. Macroeconomic Dynamics, Vol. 12, p 1-26.

[10] Quenouille, M.H. (1957) The Analysis of Multiple Time Series. London: Charles Griffin and Co. Ltd.

[11] Rahn, R. and Fox, H. (1996) What Is the Optimum Size of Government. Vernon K., Krieble Foundation. 
[12] Scully, G. (1998) Measuring the Burden of High Taxes. National Center for Policy Analysis. Policy Report No. 215.

[13] (2003) Optimal taxation, economic growth and income inequality. Public choice 115: 299 - 312.

[14] Smets, F. and Wouters, R. (2007) Shocks and Frictions in US Business Cycles: A Bayesian DSGE Approach. American Economic Review. Vol. $97,586-606$.

[15] Zarnowitz, V. (1992) Business Cycles Theory, History, Indicators, and Forecasting. NBER, Studies in Business Cycles. Vol. 27.

[16] Zellner, A. and Tobias, J. (2000) A Note on Aggregation, Disaggregation and Forecasting Performance. Journal of Forecasting. Vol. 19, 457 - 469.

[17] Zellner, A. and Israilevich, G. (2005) The Marshallian Macroeconomic Model: A Progress Report. Macroeconomic Dynamics. Vol. 9, 220 - 243.

[18] Zellner, A. and Palm, F.C. (2004) The Structural Econometric Modeling, Time Series Analysis (SEMTSA) Approach. Cambridge University Press, Cambridge. 
Table 1 - U.S. and OECD Tax Rates

\begin{tabular}{lccccc} 
Country & $\begin{array}{c}\text { Top Statutory Marginal } \\
\text { Personal Income Tax } \\
(\mathbf{2 0 0 8})\end{array}$ & $\begin{array}{c}\text { Central Gov. } \\
\text { Corporate Income } \\
\text { Tax (2009) }\end{array}$ & $\begin{array}{c}\text { Combined Corporate } \\
\text { Income Tax (2009) [1] }\end{array}$ & $\begin{array}{c}\text { Dividend } \\
\text { Income Tax } \\
(\mathbf{2 0 0 9 )}\end{array}$ & $\begin{array}{c}\text { VAT/Sales } \\
\text { Tax (2009) }\end{array}$ \\
\hline Australia & $46.5 \%$ & $30.0 \%$ & $30.0 \%$ & $46.5 \%$ & $10.0 \%$ \\
Canada & $46.4 \%$ & $19.0 \%$ & $31.3 \%$ & $47.2 \%$ & $5.0 \%$ \\
Denmark & $59.7 \%$ & $25.0 \%$ & $25.0 \%$ & $58.8 \%$ & $25.0 \%$ \\
France & $45.8 \%$ & $34.4 \%$ & $34.4 \%$ & $55.9 \%$ & $19.6 \%$ \\
Germany & $47.5 \%$ & $15.8 \%$ & $30.2 \%$ & $48.6 \%$ & $19.0 \%$ \\
Japan & $50.0 \%$ & $28.0 \%$ & $39.5 \%$ & $45.6 \%$ & $5.0 \%$ \\
Switzerland & $41.7 \%$ & $6.7 \%$ & $21.2 \%$ & $36.9 \%$ & $7.6 \%$ \\
UK & $40.0 \%$ & $28.0 \%$ & $28.0 \%$ & $46.0 \%$ & $15.0 \%$ \\
United States & $\mathbf{4 1 . 9 \%}$ & $\mathbf{3 2 . 8 \%}$ & $\mathbf{3 9 . 1 \%}$ & $\mathbf{4 9 . 6 \%}$ & $\mathbf{6 . 0 \%}$ \\
Average OECD & $41.9 \%$ & $24.0 \%$ & $26.3 \%$ & $41.4 \%$ & $17.6 \%$ \\
\hline [1] Includes State and Local Governments & & & & Source: OECD
\end{tabular}

Table 2 - Mean Absolute Errors (MAEs) and Root Mean Squared Errors (RMSEs) Associated with Use of a One-sector MMM Transfer Function's Fitted Values and Forecasted Values for U.S. Annual Growth Rates

MAE $^{*} \quad$ RMSE $^{*}$

Errors Based on Fitted Values $\quad 0.13 \quad 0.17$

(1988-2008)

$\begin{array}{lll}\text { Errors Based on One Year- Ahead Forecasts } & 0.47 & 0.66\end{array}$

(2000-2008)

Note: MAE and RMSE scores have been obtained using transfer equation of the one-sector MMM (see Table 1).

* Expressed in percentage points.

Table 3 - Mean Absolute Error (MAFE) and Root Mean Square Error (RMSFE) of Forecasts MAFE RMSFE

\begin{tabular}{lll}
\hline One quarter-ahead forecast & 0.45 & 0.58
\end{tabular}

(known exogenous variables)

\begin{tabular}{lll}
\hline One quarter-ahead forecast & 0.54 & 0.72
\end{tabular}

(forecasted exogenous variables)

Note: MAFE and RMSFE scores have been obtained using forecasts from our estimated transfer equation for the one-sector MMM using quarterly data.

* Quarterly growth rate forecast errors, expressed in percentage points of beginning of quarter real GDP. 
Table 4 - Relative Forecasting Performance of our MMM Compared to Those of a GVAR and a BVAR

\begin{tabular}{lccc}
\hline Model & Forecast Period & $\begin{array}{c}\text { Mean Squared Forecast Errors } \\
\text { (MSFEs) }\end{array}$ & $\begin{array}{c}\text { Root Mean Squared } \\
\text { Forecast Errors } \\
\text { (RMSFEs) }\end{array}$ \\
\hline Global VAR & $1991 Q 1-2003 Q 4$ & 1.24 & 1.11 \\
Bayesian VAR & $199101-2003 Q 4$ & 0.83 & 0.91 \\
DSGE & $199001-2004 Q 4$ & 3.53 & 1.88 \\
MMM & $2001 Q 1-2009 Q 3$ & 0.52 & 0.72 \\
\hline
\end{tabular}

Source for the GVAR and BVAR results: D. Giannone, and L. Reichlin. (2009). Comments on Forecasting Economic and Financial Variables with Global VARs. International Journal of Forecasting. Vol. 25, 684-686.

Source for the DSGE results: F. Smets, and R. Wouters. (2007). Shocks and Frictions in US.. Business Cycles: A Bayesian DSGE Approach. American Economic Review. Vol. 97, 586-606.

Table 5 - The One-Sector MMM with Tax Cuts Imposed in 2007 with Calculated One-Year Effects

\begin{tabular}{|c|c|c|c|}
\hline \multirow[t]{2}{*}{ Tax cut type } & \multirow[t]{2}{*}{ Nature } & \multirow{2}{*}{$\begin{array}{l}\text { Size of the change } \\
\text { (percentage points) }\end{array}$} & Economic impacts \\
\hline & & & $\begin{array}{l}\text { Increase in annual GDP growth } \\
\text { (percentage points) }\end{array}$ \\
\hline
\end{tabular}

\begin{tabular}{llll}
\hline Personal Income Tax & Permanent & $1 \%$ & $+0.6 \%$ \\
\cline { 2 - 4 } & Permanent & $5 \%$ & $+2.4 \%$ \\
\cline { 2 - 4 } & Temporary & $1 \%$ & $+0.3 \%$ \\
\cline { 2 - 4 } & Temporary & $5 \%$ & $+1.5 \%$ \\
\hline Corporate Income Tax & Permanent & $1 \%$ & $+0.2 \%$ \\
\cline { 2 - 4 } & Permanent & $5 \%$ & $+0.5 \%$ \\
\cline { 2 - 4 } & Temporary & $1 \%$ & $+0.1 \%$ \\
\cline { 2 - 4 } & Temporary & $5 \%$ & $+0.3 \%$ \\
\hline
\end{tabular}

Note: These changes have been applied to our estimated one-sector MMM (see Table 1) using U.S. annual data. 
Table 6 - One-Year Effects of Tax Rate Cuts Imposed in 2007

Sector

Percentage point increase in the sector's annual GDP growth rate

\begin{tabular}{|c|c|}
\hline Agriculture_ & $2.46(0.98)$ \\
\hline Arts, entertainment, recreation, accommodation, food service_ & $0.60(0.36)$ \\
\hline Construction_ & $0.46(0.31)$ \\
\hline Education_ & $0.11(0.19)$ \\
\hline Finance, Insurance, Real Estate, Rental, Leasing_ & $0.51(0.18)$ \\
\hline _Government_ & $0.016(0.11)$ \\
\hline Health_ & $0.12(0.24)$ \\
\hline _Information_ & $2.4(0.61)$ \\
\hline _Manufacturing_ & $1.01(0.27)$ \\
\hline Mining__ & $0.80(0.64)$ \\
\hline Other services, except Government__ & $0.28(0.18)$ \\
\hline Professional and Business Services_ & $2.01(0.32)$ \\
\hline Retail Trade_ & $1.80(0.48)$ \\
\hline _Transportation and Warehousing_ & $0.50(0.20)$ \\
\hline _Utilities_ & $0.51(0.64)$ \\
\hline _Wholesale Trade_ & $1.42(0.56)$ \\
\hline
\end{tabular}

Note: These results have been obtained using iterative seemingly unrelated regressions of our 16-sector MMM. Similar to the previous regressions, all the series with the exception of 'trade openness' have been obtained from the National and Products Account from the BEA. 'Trade openness' was obtained from the World Bank Indicators (Time Series Explorer, 2008). Values in parentheses are standard errors of forecast. The effects on real GDP growth rate are due to a 5 percentage points permanent decrease in personal and corporate income flat tax rates.

Fig.1 - Composition of U.S. Federal Government Receipts by Source

(Constant dollars of 2005)

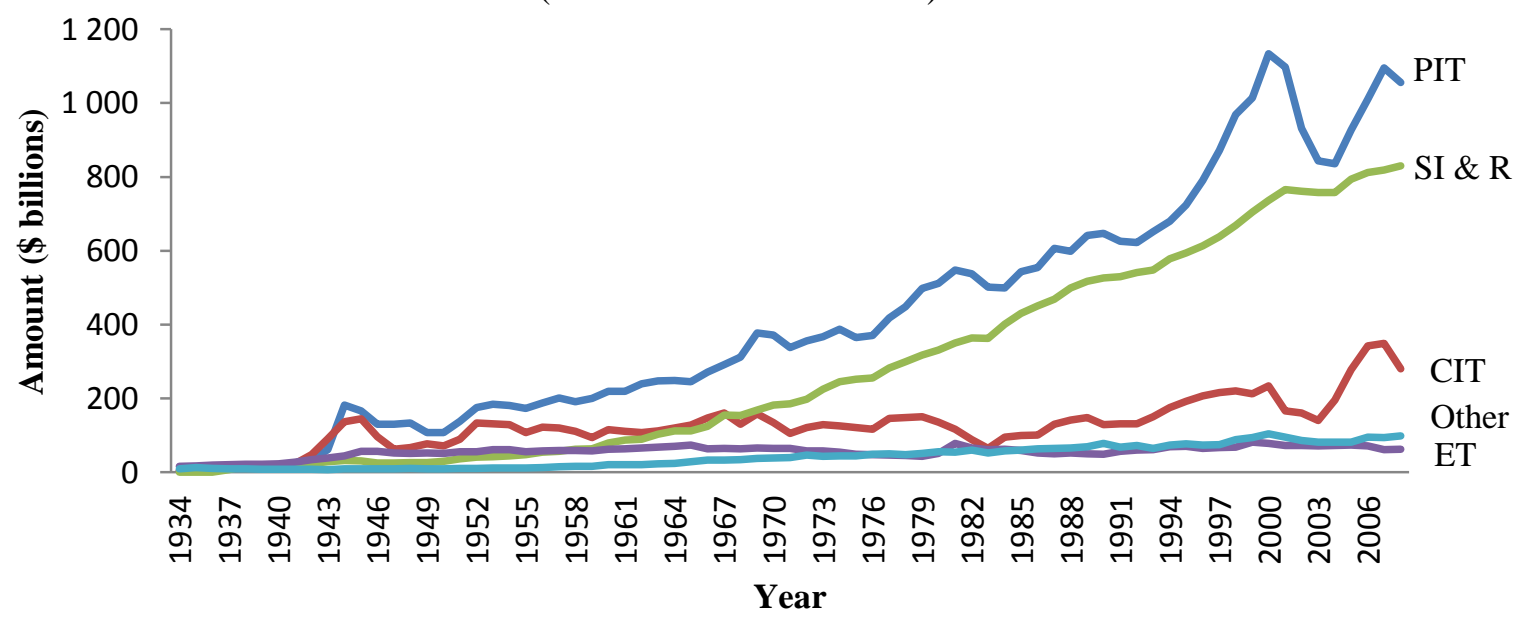



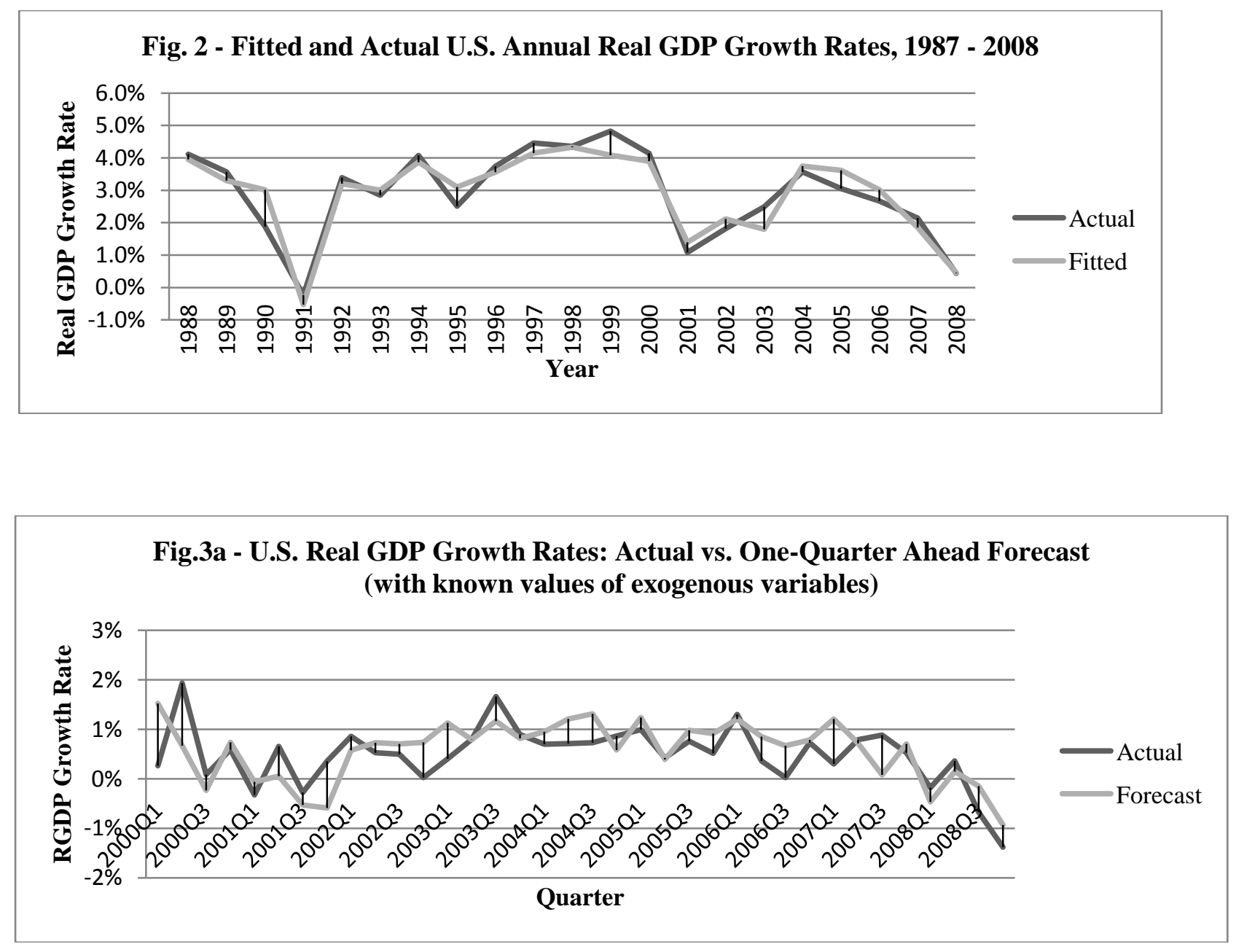

Fig. 3b - U.S. Real GDP Growth Rates: Actual vs. One-Quarter Ahead Forecast (with forecasted values of exogenous variables)

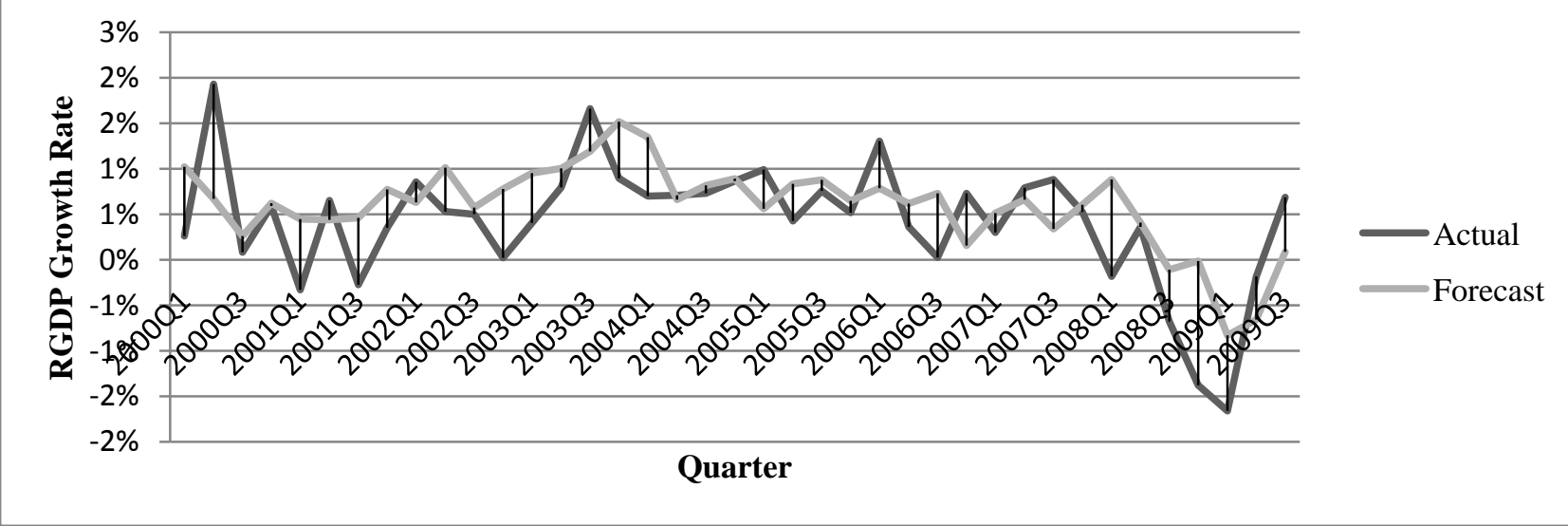


Fig.4 - U.S. Budget Deficit/Surplus with BEA Forecasts (\$ Thousands)

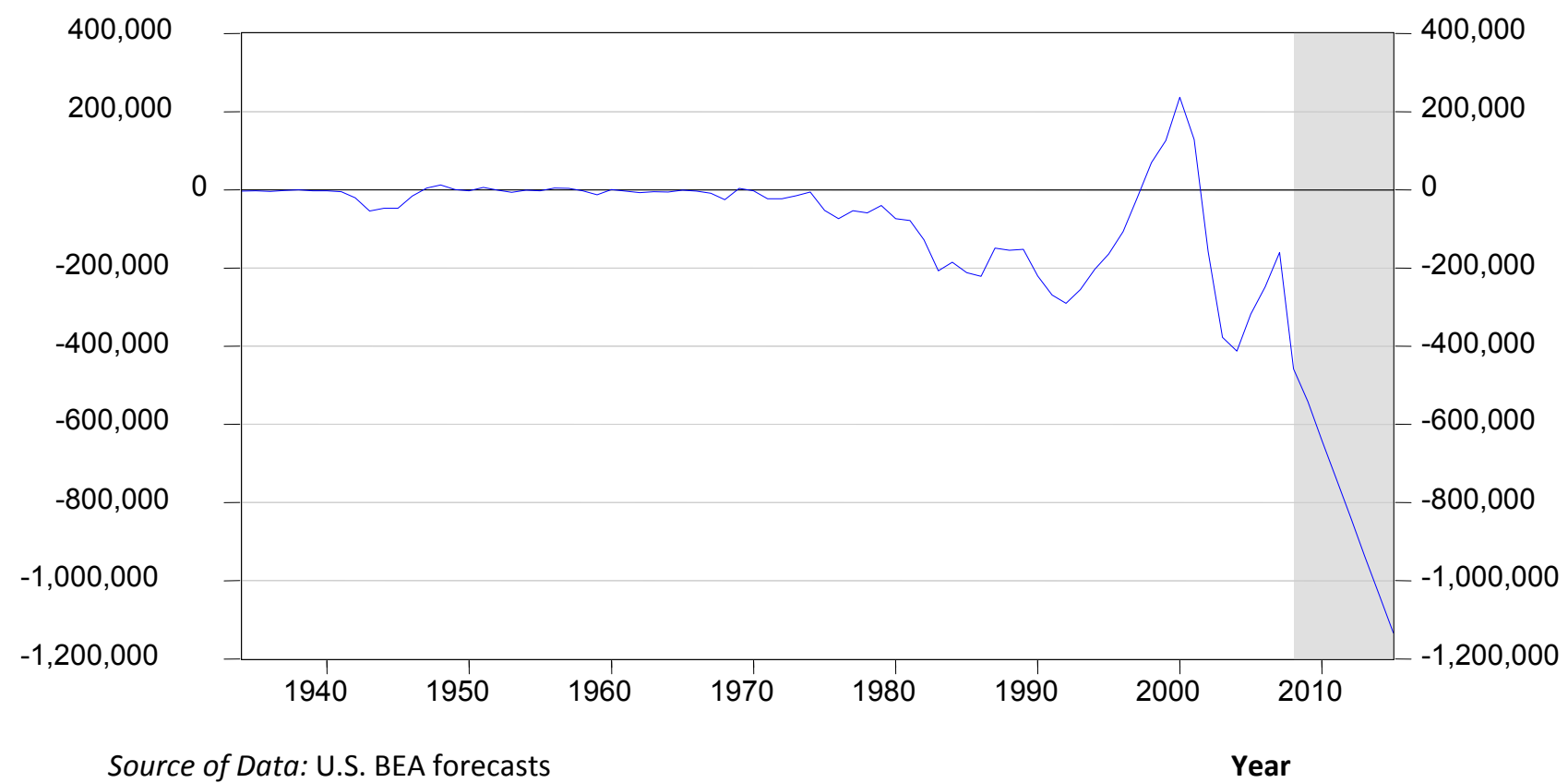

Fig.5 - U.S. Budget Deficit/Surplus (\$ Thousands): Trend, Cycle, Frequency Response Function

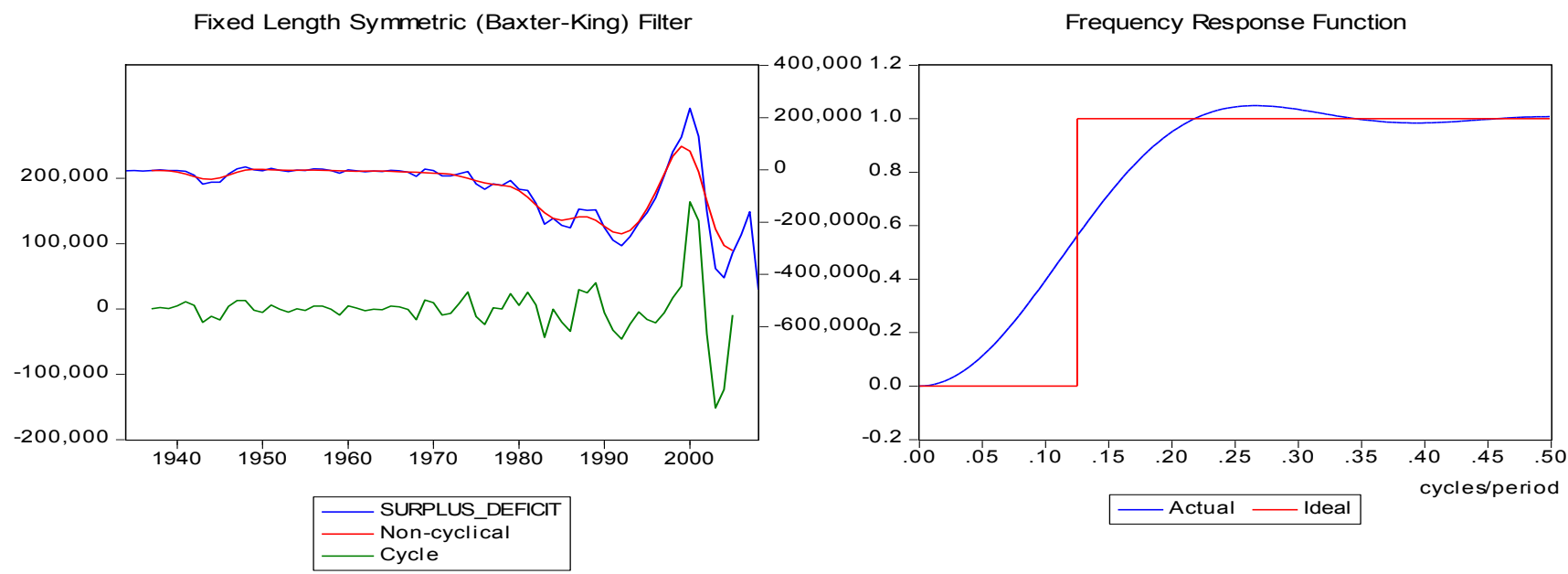

Source: Our own estimation using a Baxter-King (see Baxter and King, 1999) filter which is a function that computes cyclical and trend components of the time series using band-pass approximation for fixed and variable length filters. This filtering technique assuages drawbacks of the Hodrick-Prescot filter. 
Fig.6 - Forecasts of Budget Deficits Using Our One-Sector MMM with the Suggested Tax Cuts Deficit (\$ Thousands) Compared to U.S. BEA Forecasts - Annual Data.

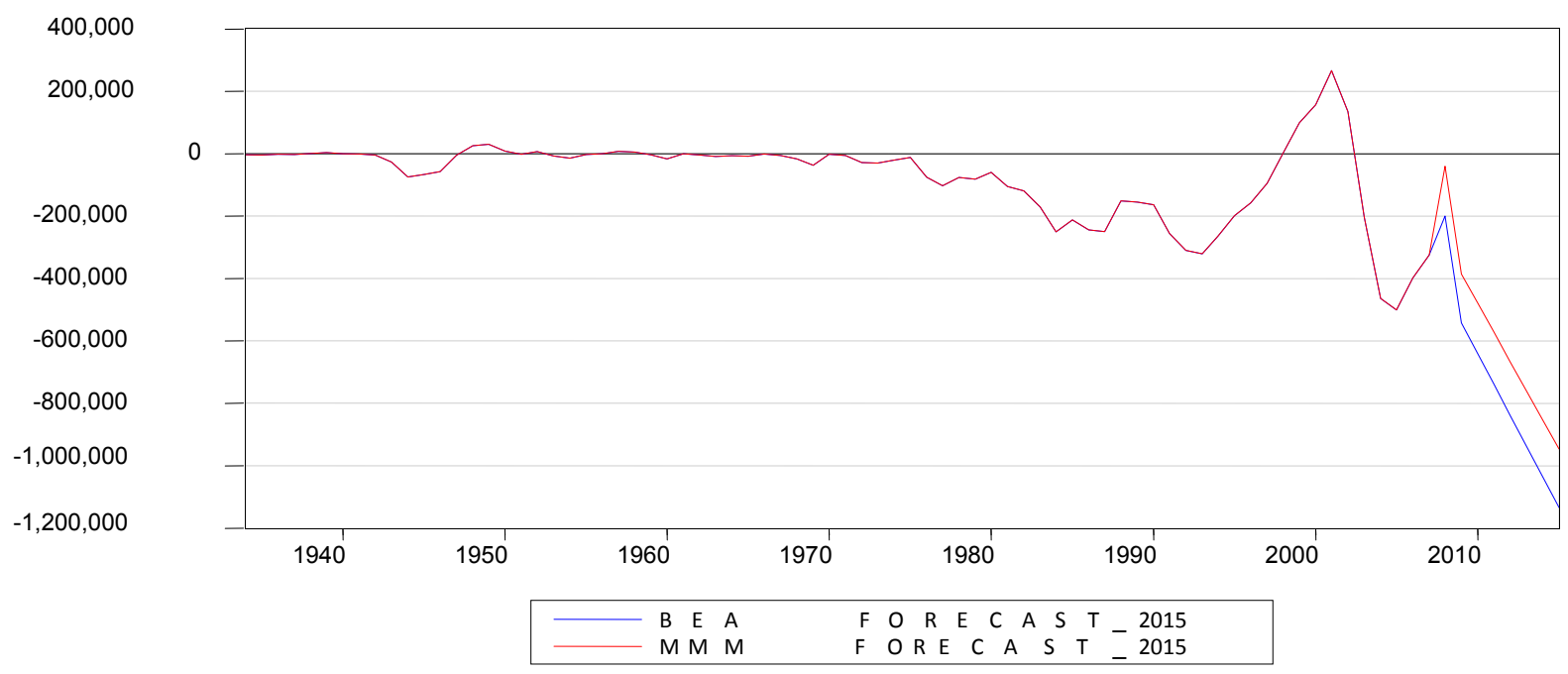

Year

Note: When we introduce a permanent 5 percentage point cut in the Personal and Corporate Income Tax rates while Government Outlays follow the historical path, the tax cut induces a 3 percentage point increase in the tax income base. 
Fig. A1 - Sectors' residual plots of real sales growth obtained from the 16-sector MMM-DA (1988 - 2007).
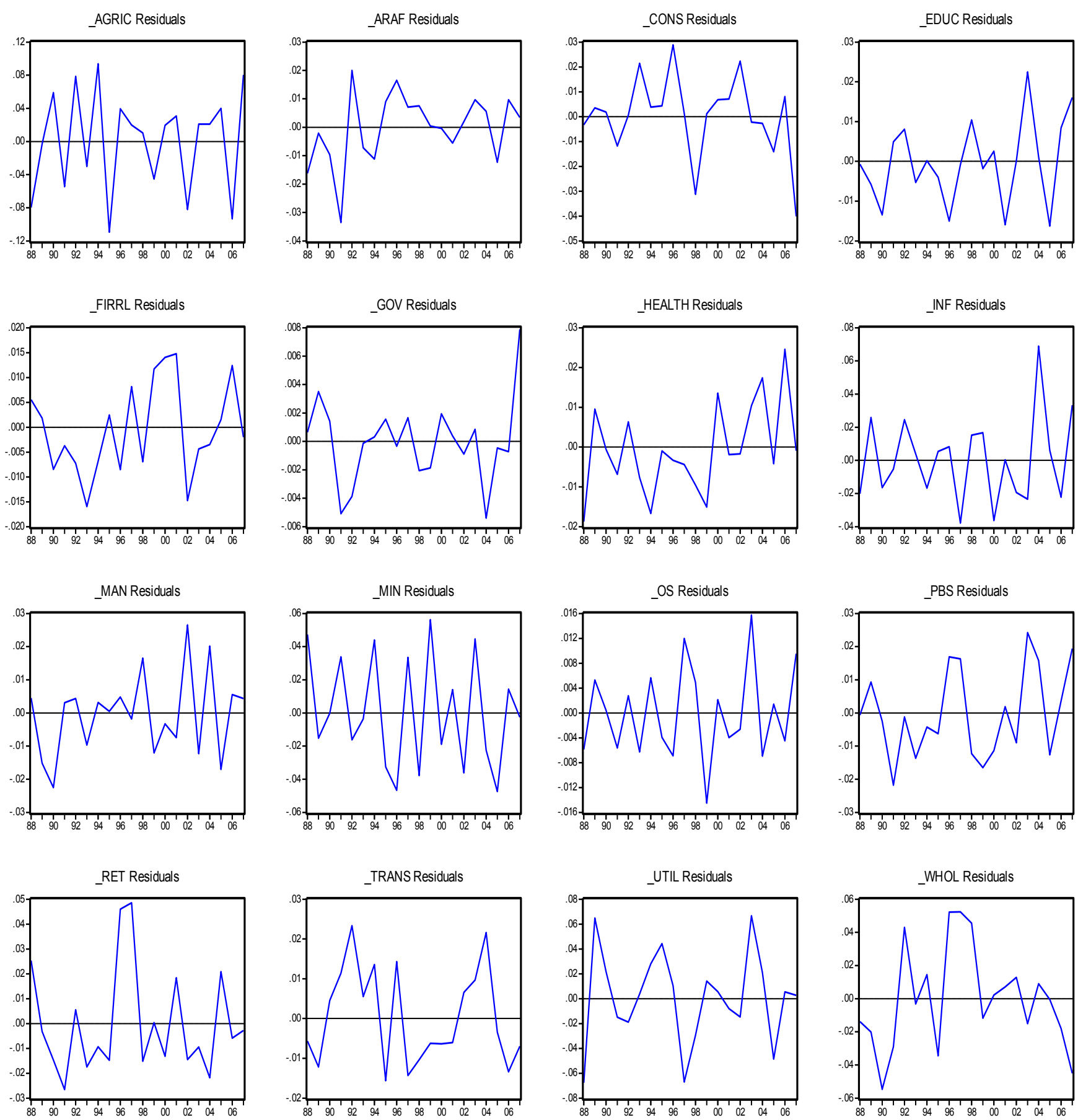
Table A1 - Box Jenkins Model identification: Estimation Results for the Autocorrelation and Partial Autocorrelation Functions

\begin{tabular}{|c|c|c|c|}
\hline Lag & $\begin{array}{l}\text { Autocorrelation } \\
\text { AC }\end{array}$ & $\begin{array}{c}\text { Partial Correlation } \\
\text { PAC }\end{array}$ & Q-Statistic \\
\hline 1 & -0.041 & -0.041 & 0.3385 \\
\hline 2 & -0.051 & -0.053 & 0.8777 \\
\hline 3 & -0.065 & -0.070 & 1.7471 \\
\hline 4 & 0.064 & 0.056 & 2.5933 \\
\hline 5 & -0.107 & -0.110 & 4.9641 \\
\hline 6 & 0.017 & 0.010 & 5.0224 \\
\hline 7 & -0.084 & -0.090 & 6.5171 \\
\hline 8 & 0.087 & 0.067 & 8.1270 \\
\hline 9 & 0.026 & 0.035 & 8.2704 \\
\hline 10 & 0.023 & 0.011 & 8.3871 \\
\hline 11 & 0.019 & 0.048 & 8.4616 \\
\hline 12 & 0.033 & 0.014 & 8.6902 \\
\hline 13 & 0.050 & 0.077 & 9.2252 \\
\hline 14 & -0.007 & 0.000 & 9.2345 \\
\hline 15 & -0.113 & -0.093 & 11.999 \\
\hline 16 & 0.114 & 0.124 & 14.838 \\
\hline 17 & -0.093 & -0.113 & 16.738 \\
\hline 18 & -0.014 & 0.001 & 16.785 \\
\hline 19 & -0.002 & 0.002 & 16.786 \\
\hline 20 & 0.022 & -0.026 & 16.898 \\
\hline 21 & -0.109 & -0.087 & 19.590 \\
\hline 22 & 0.031 & -0.025 & 19.803 \\
\hline 23 & -0.071 & -0.055 & 20.967 \\
\hline 24 & 0.064 & 0.020 & 21.900 \\
\hline 25 & 0.040 & 0.054 & 22.278 \\
\hline 26 & -0.021 & -0.035 & 22.382 \\
\hline 27 & -0.042 & -0.022 & 22.784 \\
\hline 28 & 0.042 & 0.034 & 23.195 \\
\hline 29 & 0.085 & 0.097 & 24.902 \\
\hline 30 & -0.102 & -0.093 & 27.379 \\
\hline 31 & -0.015 & 0.042 & 27.431 \\
\hline 32 & 0.059 & 0.036 & 28.271 \\
\hline 33 & 0.043 & 0.044 & 28.725 \\
\hline 34 & -0.009 & 0.040 & 28.746 \\
\hline 35 & -0.094 & -0.120 & 30.921 \\
\hline 36 & -0.007 & -0.005 & 30.933 \\
\hline
\end{tabular}

Note: AC represents the estimated coefficients of the autocorrelation function, PAC represents the coefficients of the partial autocorrelation function and Q-statistic (see Ljung-Box 1978). 